Article

\title{
Intranasal Administration of Maleic Anhydride-Modified Human Serum Albumin for Pre-Exposure Prophylaxis of Respiratory Syncytial Virus Infection
}

\author{
Zhiwu Sun ${ }^{1}$, Qian Wang ${ }^{1}$, Ran Jia ${ }^{2}$, Shuai Xia ${ }^{1}$, Yuan Li ${ }^{1}$, Qi Liu ${ }^{1}$, Wei Xu ${ }^{1}$, Jin Xu ${ }^{2}$, \\ Lanying Du ${ }^{3}$, Lu Lu ${ }^{1, *}$ and Shibo Jiang ${ }^{1,3, *}$
}

1 Key Lab of Medical Molecular Virology of MOE/MOH, Shanghai Medical College, Fudan University, 130 Dong An Rd., Xuhui District, Shanghai 200032, China;

E-Mails: haoyunzhiwu@163.com (Z.S.); miaqian@foxmail.com (Q.W.); 928958768@qq.com (S.X.); liyuan.mic@gmail.com (Y.L.); qiliu@aliyun.com (Q.L.); xuwei0576@126.com (W.X.)

2 Laboratory Medicine Center, Pediatric Institute, Children's Hospital of Fudan University, 399 Wanyuan Road, Shanghai, 201102, China; E-Mails: goodbye_sea@126.com (R.J.); jinxu_125@163.com (J.X.)

3 Lindsley F. Kimball Research Institute, New York Blood Center, New York, NY 10065, USA; E-Mail: lanydu2007@gmail.com (L.D.)

* Authors to whom correspondence should be addressed; E-Mails: lul@fudan.edu.cn (L.L.); shibojiang@fudan.edu.cn (S.J.); Tel.: +86-021-54237673 (S.J.); Fax: +86-021-54237671 (L.L.).

Academic Editor: Curt Hagedorn

Received: 16 October 2014 / Accepted: 10 February 2015 / Published: 16 February 2015

\begin{abstract}
Respiratory syncytial virus (RSV) is the leading cause of pediatric viral respiratory tract infections. Neither vaccine nor effective antiviral therapy is available to prevent and treat RSV infection. Palivizumab, a humanized monoclonal antibody, is the only product approved to prevent serious RSV infection, but its high cost is prohibitive in low-income countries. Here, we aimed to identify an effective, safe, and affordable antiviral agent for pre-exposure prophylaxis (PrEP) of RSV infection in children at high risk. We found that maleic anhydride (ML)-modified human serum albumin (HSA), designated ML-HSA, exhibited potent antiviral activity against RSV and that the percentages of the modified lysines and arginies in ML- are correlated with such anti-RSV activity. ML-HSA inhibited RSV entry and replication by interacting with viral G protein and blocking RSV attachment to the target cells, while ML-HAS neither bound to
\end{abstract}


$\mathrm{F}$ protein, nor inhibited $\mathrm{F}$ protein-mediated membrane fusion. Intranasal administration of ML-HSA before RSV infection resulted in significant decrease of the viral titers in the lungs of mice. ML-HSA shows promise for further development into an effective, safe, affordable, and easy-to-use intranasal regimen for pre-exposure prophylaxis of RSV infection in children at high risk in both low- and high-income countries.

Keywords: human serum albumin (HSA); pre-exposure prophylaxis (PrEP); respiratory syncytial virus (RSV); entry inhibitor; antiviral

\section{Introduction}

Human respiratory syncytial virus (RSV), a member of the paramyxoviridae family of negativesense RNA viruses, is the leading cause of virus-induced severe lower respiratory tract disease in infants and children as well as morbidity and mortality in elderly people and immunocompromised adults [1-3]. An estimated 33.8 million cases of acute lower respiratory infection (ALRI) caused by RSV infection in children younger than 5 years occurred in 2005, and about 66,000-199,000 of these infected children died from ALRI [4]. In the United States, about 125,000 hospitalizations and 2.1 million children under 5 years of age require medical attention each year because of RSV infection [5]. Virtually every child has been infected by RSV at any given age [6,7].

Neither vaccine nor effective antiviral therapy is currently available to prevent and treat RSV infection. Palivizumab (trade name: Synagis) is a humanized murine monoclonal antibody (mAb) specific for RSV F glycoprotein with neutralizing and fusion inhibitory activity against RSV. It has been approved by the U.S. Food and Drug Administration (FDA) as passive immunoprophylaxis for use among infants at high risk, including those born prematurely and those with chronic lung disease or congenital heart disease [8-10]. However, its high cost $(\$ 2,962$ per $100-\mathrm{mg}$ vial of palivizumab in June 2013) prevents its use in low-income countries [11], and as a mAb, it has to be maintained and transported under low temperature. Furthermore, palivizumab must be prescribed by pediatricians or physicians and intramuscularly injected at doctors' offices, hospitals, or clinics, making its use inconvenient. An ideal prophylactic RSV drug should be effective, safe, affordable and easy to use for both infants and the elderly. Therefore, we aimed to identify an antiviral agent that is expected to be as effective and safe as palivizumab, but more affordable and easier to use for pre-exposure prophylaxis (PrEP) of RSV infection among infants at high risk.

Our previous studies have demonstrated that anhydride-modified proteins exhibit potent antiviral activities against human immunodeficiency virus 1 (HIV-1), herpes simplex virus (HSV) and human papillomavirus (HPV) [12-14]. Here, we found that anhydride-modified proteins, particularly 3-hydroxyphthalic anhydride (HP) and maleic anhydride (ML) modified bovine albumin (BSA) and human serum albumin (HSA), exhibited potent inhibitory activities against RSV. We selected ML-modified HSA (ML-HSA) for further study because ML is much cheaper than HP, while HSA is much safer than BSA for human use. The mechanism study indicated that ML-HSA inhibits RSV entry and replication by blocking RSV attachment to the target cells though its interaction with viral G protein. Intranasal administration of ML-HSA before RSV challenge led to significant decrease of 
viral titers in the lungs of mice, suggesting that ML-HSA may be used for PrEP of RSV infection in children at high risk.

\section{Materials and Methods}

\subsection{Reagents}

3-hydroxyphthalic anhydride (HP), maleic anhydride (ML), succinic anhydride (SU), human serum albumin (HSA), chicken ovalbumin (OVA), bovine serum albumin (BSA), and $\beta$-lactoglobulin ( $\beta$-LG) were purchased from Sigma (St. Louis, MO, USA). Cell Counting Kit-8 (CCK-8) was bought from Dojindo Molecular Technologies, Inc. (Dojindo, Japan). 2,4,6-trinitrobenzenesulfonic acid (TNBS) was purchased from Sigma. $\rho$-hydroxyphenylglyoxal ( $\rho-\mathrm{HPG}$ ) was purchased from Fisher Scientific Co. (Valley Park, VA, USA). BMS433771 and TMC353121 were purchased from Sigma. Anti-RSV antibody (NCL-RSV3) was from Leica Biosystems (Leica Biosystems Newcastle Ltd., Newcastle Upon Tyne, UK). Rabbit anti-mouse HRP antibody was purchased from Dako (Dako, Glostrup, Denmark). Low melting point agarose was bought from Invitrogen (Invitrogen, Carlsbad, CA, USA).

\subsection{Cells, Virus and Plasmid}

HEp-2 cells and Vero cells were obtained from American Type Culture Collection (ATCC). Flp-In 293 cells were obtained from Invitrogen. They were maintained in Eagle's minimal essential medium (DMEM) (Gibco/BRL, Grand Island, NY, USA), supplemented with 5\% fetal bovine serum (FBS) from Gibco, $2 \mathrm{mM}$ L-glutamine, $100 \mathrm{U}$ of penicillin and $100 \mathrm{ng}$ of streptomycin per $\mathrm{mL}$. RSV Long Strain was purchased from ATCC and grown in HEp-2 cells. The pcDNA5/FRT/TO and pOG44 vectors were purchased from Invitrogen. The pUC57-F vector encoding the F protein of RSV A2 was provided by Dr. Bin Wang at Fudan University.

\subsection{Determination of RSV Titer}

Viral titer was determined by plaque assay as previously described [15]. Briefly, serial 10-fold dilutions of RSV Long Strain/A2 strain in DMEM with 2\% FBS were used to infect HEp-2 monolayers on 24 -well plates at $1 \times 10^{5}$ cells per well in duplicates for $3 \mathrm{~h}$ at $37{ }^{\circ} \mathrm{C}$. After virus attachment to cells, the inocula were removed and washed with phosphate buffer solution (PBS). The infected cells were overlaid with $2 \%$ FBS in DMEM containing 0.5\% low melting point agarose and incubated at $37{ }^{\circ} \mathrm{C}$. Five days later, plaques were developed, and cells were fixed with $4 \%$ paraformaldehyde. After removal of agarose, viral plaques were visualized by immunoperoxidase staining with mouse anti-RSV (NCL-RSV3) antibody as the primary antibody (1:500 in PBS) and HRP-conjugated rabbit anti-mouse IgG as the secondary antibody (1:250 dilution in PBS). HRP Color Development Reagent (4CN, Bio-Rad, Hercules, CA, USA) was used for color development of plaques.

\subsection{Chemical Modification of Proteins with Different Anhydrides under Variable Conditions}

Protein modification was conducted as previously described [13]. Briefly, the proteins were dissolved in $0.1 \mathrm{M}$ phosphate (final concentration, $20 \mathrm{mg} / \mathrm{mL}$ ). Subsequently, 3-hydroxyphthalic 
anhydride (HP), maleic anhydride (ML) or succinic anhydride (SU) was added, respectively, in five aliquots with a 12-min interval, while $\mathrm{pH}$ was adjusted to 9.0. To optimize the condition of anhydride modification, HSA was modified with $2.5,5,10,20,40$ or $60 \mathrm{mM}$ anhydride (HP, ML or SU), respectively. The mixtures were kept for another $1 \mathrm{~h}$ at room temperature and then extensively dialyzed against PBS.

Protein concentrations were determined with the Pierce BCA Protein Assay Kit (Thermo, Rockford, IL, USA). To determine lysine residues in modified or unmodified proteins, TNBS assay was performed as previously described [16,17]. Briefly, $25 \mu \mathrm{L} \mathrm{Na}_{2} \mathrm{~B}_{4} \mathrm{O}_{7}(0.1 \mathrm{M}, \mathrm{pH} 8.5)$ were added to $25 \mu \mathrm{L}$ modified or unmodified proteins for $5 \mathrm{~min}$ at room temperature. Then, $3 \mu \mathrm{L}$ of TNBS and $7 \mu \mathrm{L}$ of PBS were added to the mixture. After $1 \mathrm{~h}$, a $100-\mu \mathrm{L}$ stop solution $\left(0.1 \mathrm{M} \mathrm{NaH}_{2} \mathrm{PO}_{4}\right.$ and $1.5 \mathrm{mM}$ $\mathrm{Na}_{2} \mathrm{SO}_{3}$ ) was added to terminate the reaction. The absorbance at $420 \mathrm{~nm}$ (A420) was measured with a microplate reader (Infinite M200 Pro, Tecan, Research Triangle Park, NC, USA). The assay utilized to measure the percentage of arginine residue modification was performed as previously described [18,19]. $\rho$-HPG $(10 \mu \mathrm{L}, 50 \mathrm{mM})$ was added to $90 \mu \mathrm{L}$ anhydride-modified or unmodified proteins dissolved in $0.1 \mathrm{M}$ sodium phosphate $(\mathrm{pH} 9.0)$ and kept at room temperature in the dark for $90 \mathrm{~min}$. The absorbance at $340 \mathrm{~nm}\left(\mathrm{~A}_{340}\right)$ was measured.

\subsection{Cytotoxicity Assay}

The in vitro cytotoxicity of the anhydride-modified and unmodified HSA to the target cells used for measuring RSV infectivity (HEp-2 and Vero) was measured with a CCK-8 kit, according to the manufacturer's instructions [20]. Briefly, $100 \mu \mathrm{L}$ of modified and unmodified proteins at graded concentrations were added to equal volumes of cells $\left(4 \times 10^{4} / \mathrm{mL}\right)$ in wells of 96 -well plates. After incubation at $37{ }^{\circ} \mathrm{C}$ for 4 days, $10 \mu \mathrm{L}$ of CCK-8 solution were added. After $4 \mathrm{~h}$ of incubation, the absorbance at $450 \mathrm{~nm}$ (A450) was determined with an ELISA reader (Infinite M200 Pro).

\subsection{Assay for Cell Protection of Anhydride-Modified Proteins against RSV}

An assay for cell protection, as described previously [21], was used to assess the antiviral activities of anhydride-modified proteins. In brief, HEp-2 cells were seeded into a 96-well plate at 4000 cells per well; then serially diluted proteins were added to the plated HEp-2 cells and infected the with $4.0 \times 10^{2}$ plaque-forming unit $(\mathrm{PFU})$ of RSV Long Strain $(\mathrm{MOI}=0.1)$. After culture at $37^{\circ} \mathrm{C}$ for five days, the cell viability was examined by CCK-8 kit as described above.

\subsection{Time-of-Addition and Temperature Shift Assays}

To investigate the mechanism of action of ML-HSA against RSV, time-of-addition and temperature shift assays were performed as previously described [22-24]. Monolayer cultures of HEp-2 cells were infected with $2 \times 10^{5}$ PFU (MOI = 2) of RSV Long Strain in the absence or presence of ML-HSA (final concentration, $2000 \mathrm{nM}$ ). ML-HSA was added to the plates at $0,0.5,1,2,3$, 5, or $7 \mathrm{~h}$ post-infection. At $20 \mathrm{~h}$ post-infection, supernatants were collected, and inhibition of RSV infection was determined by plaque assay as described above. In temperature shift assays, HEp-2 cells were plated as described above and exposed to RSV Long Strain at $4{ }^{\circ} \mathrm{C}$ in the presence of various amounts 
of ML-HSA. Heparin, an RSV attachment inhibitor [24], was included as a control. After $1 \mathrm{~h}$ of incubation, cells were washed with ice-cold PBS twice and replaced with fresh medium. As a control, cells in the presence of ML-HSA or heparin were not washed. The plates were then moved to an incubator at $37^{\circ} \mathrm{C}$. After culture at $37{ }^{\circ} \mathrm{C}$ for 5 days, the cytopathic effect (CPE) was determined with CCK-8 kit as described in the previous section.

\subsection{Cell-Cell Fusion Assay}

To investigate whether ML-HSA could inhibit RSV F protein-mediated cell-cell fusion or syncytium formation, we performed a cell-cell fusion assay based on the fact that RSV F protein expressed on the cell surface can mediate cell fusion with neighboring cells [2,25]. To construct the 293-F cells expressing F protein of RSV, F gene of RSV A2 fused with GFP at its C-terminus was cloned into pcDNA5/FRT/TO vector (pcDNA5/FRT/TO-F). Then pcDNA5/FRT/TO-F and pOG44 were co-transfected into the Flp-In 293 cells with a 1:9 ratio. After $48 \mathrm{~h}$ of transfection, cells were split and added with $200 \mu \mathrm{g} / \mathrm{mL}$ Zeocin (Invitrogen) and $100 \mu \mathrm{g} / \mathrm{mL}$ Hydromycin B (Invitrogen). Then, $2 \times 10^{5} 293$-F cells per well were seeded at 24 -well plate. After incubation at $37{ }^{\circ} \mathrm{C}$ for $24 \mathrm{~h}, 2 \mu \mathrm{g} / \mathrm{mL}$ tetracycline and 1\% DMSO was added to induce the F protein expression on the 293-F cells. ML-HSA (1000 nM), HSA (1000 nM), and TMC353121 (200 nM, an F protein inhibitor) [26], were added to the 293-F cells. After coculture for $48 \mathrm{~h}$, the cell-cell fusion or syncytium formation was visualized by microscopy (Nikon, Eclipse TS 100, Nikon, Tokyo, Japan).

\subsection{ELISA Assay}

To determine the interaction between ML-HSA and RSV G protein, we performed an ELISA assay as previously described [27]. Briefly, RSV G protein (extracellular domain, provided by Dr. B. Wang at Fudan University) at $5 \mu \mathrm{g} / \mathrm{mL}$ was coated on 96 -well plates and incubated overnight at $4{ }^{\circ} \mathrm{C}$. Plates were blocked with $1 \%$ gelatin in PBS for $1 \mathrm{~h}$ at $37^{\circ} \mathrm{C}$, followed by incubation with HSA or ML-HSA serially diluted in PBS for $30 \mathrm{~min}$ at $37^{\circ} \mathrm{C}$. Anti-HSA antibody (Abcam, Hong Kong) was added at $1.5 \mu \mathrm{g} / \mathrm{mL}$ and incubated for $1 \mathrm{~h}$ at $37^{\circ} \mathrm{C}$. Horseradish peroxidase (HRP)-conjugated goat anti-human IgG antibody (Dako, Glostrup, Denmark) at 1:2500 dilution was added and incubated at $37{ }^{\circ} \mathrm{C}$ for $1 \mathrm{~h}$. Plates were washed between each step with $0.05 \%$ Tween 20 in PBS. Plates were developed using 3,3',5,5'-tetramethylbenzidine (TMB) peroxidase substrate (Sigma), and absorbance at $450 \mathrm{~nm}$ (A450) was measured using an ELISA reader (Infinite M200 Pro). The interaction between ML-HSA and RSV $\mathrm{F}$ protein was also determined by ELISA described above. F protein was purchased from Sino Biological Inc. (Beijing, China). In the control assay, $10 \mu \mathrm{g} / \mathrm{mL}$ each of HSA and ML-HSA were coated on 96-well plates, and ELISA assay was performed as described above.

\subsection{Selection of Drug-Resistant Virus}

Drug-resistant RSV strains were selected and purified as previously described [28,29]. Briefly, $8 \times 10^{5} \mathrm{HEp}-2$ cells were seeded on 6-well plates (Corning, Acton, MA, USA). Cells were infected with RSV Long Strain (wild-type strain) at an MOI $>1$ in the presence or absence of ML-HSA at increasing concentration (starting at $63 \mathrm{nM}$ and gradually increasing to $3690 \mathrm{nM}$ ). The virus was then 
passaged continuously until it showed resistance to ML-HSA. The wild-type strain was passaged without drugs in parallel. Following 8 passages of the RSV Long Strain in the presence of ML-HSA, the first resistant strain was obtained $\left(\mathrm{IC}_{50}=8.39 \mathrm{nM}\right)$. At passage 15 under ML-HSA pressure, the second resistant virus strain $\left(\mathrm{IC}_{50}=201 \mathrm{nM}\right)$ was obtained and used as the resistant strain for sequence analysis.

\subsection{RSV-RNA Extraction and RT-PCR Amplification}

Viral RNA was extracted from supernatant of the RSV-infected HEp-2 cells using a commercial kit (High Pure Viral Nucleic Acid kit, Roche Diagnostics, Indianapolis, IN, USA). For gene amplification, primers were used as described in previous studies [28]. The specific $G$ primers were used to perform the reverse transcription of viral RNA to acquire the specific cDNA of the G genes. Briefly, $2 \mu \mathrm{L}$ each of extracted RNA and $1 \mu \mathrm{L}$ of primer were combined with $0.5 \mathrm{mM}$ dNTP mixture, first-strand buffer, $10 \mu \mathrm{M}$ DTT, and 40 units of SuperScript ${ }^{\mathbb{R}}$ IIRNase $\mathrm{H}^{-}$transcriptase (Invitrogen) in $20 \mu \mathrm{L}$ of reaction volume. The mixture was incubated at $42{ }^{\circ} \mathrm{C}$ for $50 \mathrm{~min}$ and followed by heating at $70{ }^{\circ} \mathrm{C}$ for $15 \mathrm{~min}$. RSV G protein genes were amplified from the specific cDNAs gained as above by nested PCR using PrimeSTAR ${ }^{\circledR}$ HS DNA Polymerase (TakaRa, Japan) and the primer sets and cycle parameters as described in previous research [28]. PCR products from the second round were, as expected, 1088 base pairs (bp), and they were visualized by electrophoresis on a $0.8 \%$ agarose gel stained with ethidium bromide.

\subsection{Mouse Models of RSV Infection}

Female BALB/c mice six to eight weeks of age were purchased from the Animal Center of Fudan University (Shanghai, China). Mice were housed in cages with barrier filters in certified rooms and were fed and watered ad libitum. The protocol for the use of animals in this study was approved by the Animal Center of Fudan University (Permit number: 2013N-067). The animal studies were conducted in strict accordance with the recommendations in the Guide for the Care and Use of Laboratory Animals.

A mouse model of RSV infection was used to examine the in vivo inhibitory activity of ML-HSA as described previously [30-32]. Briefly, BALB/c mice were chemically immunosuppressed by intraperitoneal injection of $100 \mathrm{mg}$ of cyclophosphamide (Sigma) per $\mathrm{kg}$ of body weight 6 days and 1 day prior to RSV infection. The mice were intranasally administered with different doses of ML-HSA mixed with $2.1 \times 10^{5}$ PFU RSV. Four days after RSV infection, the mice were sacrificed. Lung homogenates $(10 \%$; wt/vol) were prepared in Hanks balanced salt solution containing $0.21 \mathrm{M}$ sucrose, $25 \mathrm{mM}$ HEPES, and $5 \mathrm{mM}$ sodium L-glutamate supplemented with $20 \mathrm{U} / \mathrm{mL}$ of penicillin G, $20 \mu \mathrm{g} / \mathrm{mL}$ of streptomycin, and $0.05 \mu \mathrm{g} / \mathrm{mL}$ of amphotericin B (Sigma). Lung homogenates were frozen on dry ice and thawed to release cell-associated virus. Samples of lung homogenates were centrifuged at $300 \times g$ for $10 \mathrm{~min}$ at $4{ }^{\circ} \mathrm{C}$, and the supernatants were collected for viral titration in HEp-2 cells. In brief, each test sample was assayed in duplicate sets of serial 3.17-fold dilutions in serum-free DMEM supplemented with $2 \mathrm{mM}$ L-glutamine, $100 \mathrm{U}$ of penicillin and $100 \mu \mathrm{g}$ of streptomycin per mL. Each $200-\mu \mathrm{L}$ diluted sample was plated to HEp-2 cells in flat-bottom 24-well polystyrene plates (Corning, Acton, MA, USA). Then plaque assay was performed as described above. 
To evaluate the prophylactic effect of ML-HSA, mice were intranasally administered with ML-HSA at different concentration. About $30 \mathrm{~min}$ or $15 \mathrm{~min}$ later, the mice were intranasally inoculated with $2.1 \times 10^{5}$ PFU of RSV, respectively. After 4 days, the mice were sacrificed, and the viral titer in the lung homogenates was determined as described above.

\section{Results}

\subsection{Anhydride-Modified Proteins were Potent Inhibitors against RSV Infection}

Previous studies have demonstrated that bovine milk proteins modified with anhydride become highly potent inhibitors against HIV-1 and HPV infection [12,13]. With a similar approach, we modified four proteins, including $\beta$-LG, BSA, OVA and HSA, with HP, ML and SU, respectively. Their antiviral activities against infections of RSV A2 and Long Strain were tested. As shown in Table 1, except HP that showed moderate inhibitory activity at high concentration, ML and SU exhibited no inhibition at the concentration up to $10 \mu \mathrm{M}$. However, all of these modified proteins exhibited highly effective antiviral activities against both A2 and Long strains with $\mathrm{IC}_{50}$ s at the nanomolar level. The anhydride-modified BSA and HSA were more efficacious than the other two anhydride-modified proteins, while the RSV A2 strain was more sensitive than the RSV Long Strain to the anhydride-modified proteins. Although anhydride-modified BSA exhibited anti-RSV activity similar to anhydride-modified HSA, we selected anhydride-modified HSA for further studies because some infants may be allergic to BSA, a bovine protein, but not HSA, a human protein.

Table 1. Comparison of the anti-respiratory syncytial virus (RSV) activities of different proteins modified by distinct anhydrides.

\begin{tabular}{|c|c|c|c|c|}
\hline \multirow{3}{*}{$\begin{array}{l}\text { Anhydride-Modified } \\
\text { Protein }\end{array}$} & \multicolumn{4}{|c|}{ Inhibition of Infection by } \\
\hline & \multicolumn{2}{|c|}{ RSV A2 Strain } & \multicolumn{2}{|c|}{ RSV Long Strain } \\
\hline & $\mathrm{IC}_{50}(\boldsymbol{\mu M})$ & $\mathrm{IC}_{90}(\mu \mathrm{M})$ & $\mathrm{IC}_{50}(\boldsymbol{\mu M})$ & $\mathrm{IC}_{90}(\mu \mathrm{M})$ \\
\hline HP & $3.142 \pm 0.458$ & $>10$ & $5.832 \pm 0.753$ & $>10$ \\
\hline HP- $\beta-L G$ & $0.062 \pm 0.011$ & $0.227 \pm 0.029$ & $0.153 \pm 0.011$ & $0.422 \pm 0.021$ \\
\hline HP-OVA & $0.013 \pm 0.002$ & $0.052 \pm 0.009$ & $0.100 \pm 0.007$ & $0.517 \pm 0.121$ \\
\hline HP-HSA & $0.006 \pm 0.001$ & $0.042 \pm 0.022$ & $0.011 \pm 0.003$ & $0.056 \pm 0.010$ \\
\hline HP-BSA & $0.005 \pm 0.001$ & $0.025 \pm 0.010$ & $0.016 \pm 0.004$ & $0.099 \pm 0.011$ \\
\hline ML & $>10$ & $>10$ & $>10$ & $>10$ \\
\hline ML- $\beta-L G$ & $0.283 \pm 0.130$ & $1.046 \pm 0.263$ & $0.173 \pm 0.045$ & $0.581 \pm 0.091$ \\
\hline ML-OVA & $0.024 \pm 0.011$ & $0.077 \pm 0.033$ & $0.217 \pm 0.005$ & $1.425 \pm 0.143$ \\
\hline ML-HSA & $0.012 \pm 0.002$ & $0.038 \pm 0.003$ & $0.002 \pm 0.001$ & $0.013 \pm 0.005$ \\
\hline ML-BSA & $0.002 \pm 0.000$ & $0.026 \pm 0.019$ & $0.007 \pm 0.002$ & $0.025 \pm 0.005$ \\
\hline SU & $>10$ & $>10$ & $>10$ & $>10$ \\
\hline SU- $\beta-L G$ & $0.599 \pm 0.079$ & $1.388 \pm 0.112$ & $0.405 \pm 0.100$ & $1.093 \pm 0.209$ \\
\hline SU-OVA & $0.046 \pm 0.008$ & $0.172 \pm 0.024$ & $0.277 \pm 0.077$ & $1.173 \pm 0.321$ \\
\hline SU-HSA & $0.011 \pm 0.005$ & $0.049 \pm 0.021$ & $0.014 \pm 0.005$ & $0.110 \pm 0.070$ \\
\hline SU-BSA & $0.006 \pm 0.001$ & $0.047 \pm 0.011$ & $0.026 \pm 0.015$ & $0.125 \pm 0.020$ \\
\hline
\end{tabular}

Each sample was tested in triplicate, and the experiment was repeated twice. The data from one representative experiment were presented in mean $\pm \mathrm{SD}$. 

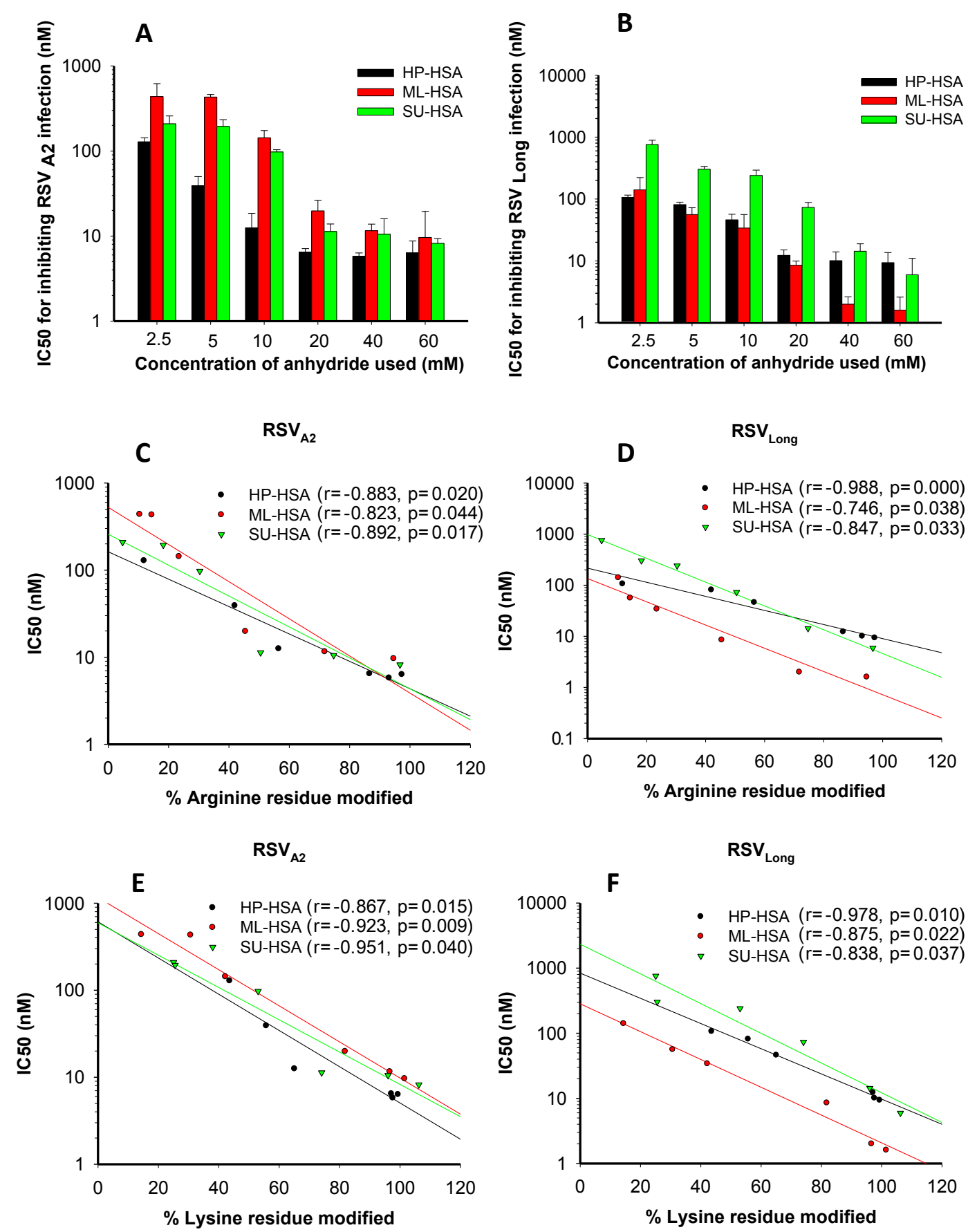

Figure 1. The effects of anhydride concentrations in the reaction system on anti-RSV activity of the HP-, ML-, and SU-modified human serum albumin (HSA) and the correlation between the percentages of modified residues and anti-RSV activity of the modified HSA. The IC 50 values of HSA modified with HP, ML, and SU, respectively, for inhibiting infection by RSV A2 Strain (A) and Long Strain (B). The correlation between the percentages of the modified arginine residues and the antiviral activities of the modified HSA against RSV A2 Strain (C) and Long Strain (D). The correlation between the percentages of lysine residues and the antiviral activities of the modified HSA against RSV A2 strain (E) and Long Strain (F). Each sample was tested in triplicate, and the experiment was repeated twice. The data from one representative experiment were presented in mean $\pm \mathrm{SD}$. 
A

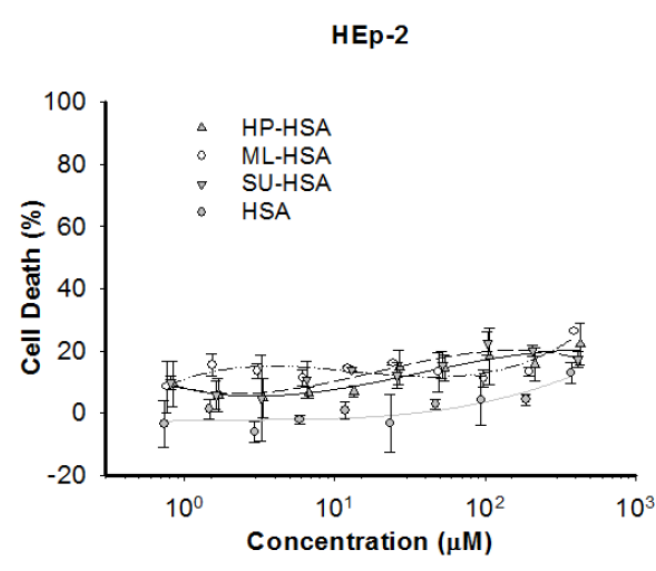

C

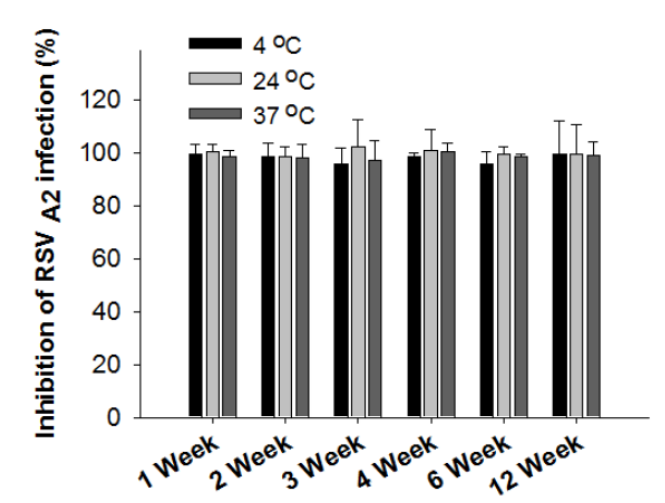

B

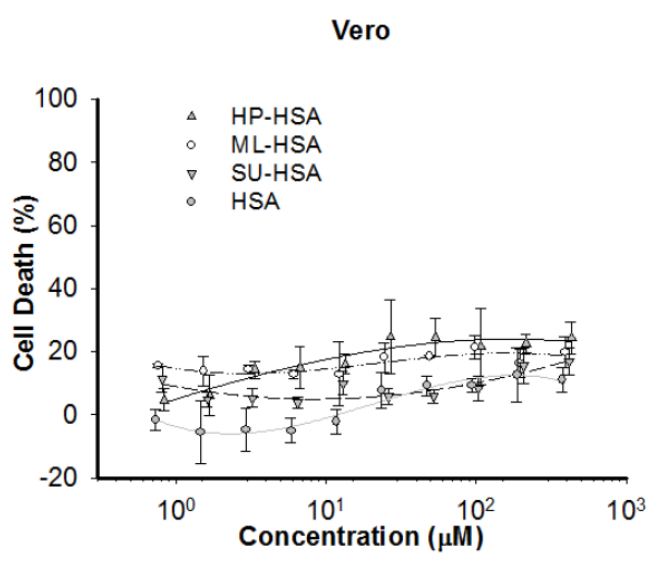

D

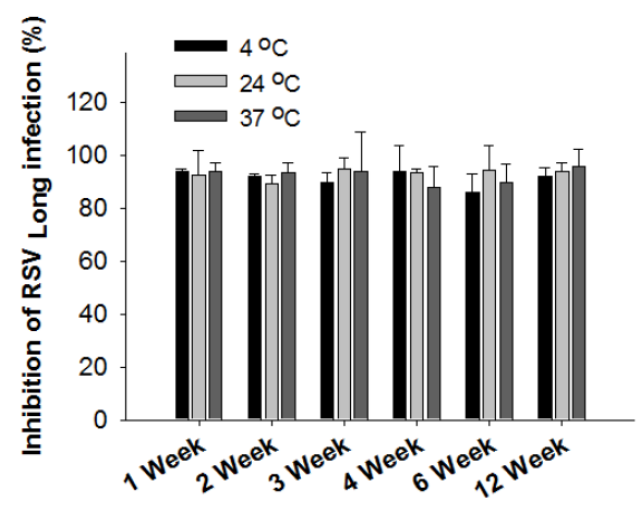

Figure 2. Cytotoxicity of different anhydride-modified HSA and the stability of ML-HSA. Cytotoxicity of HSA modified with HP, ML, and SU, respectively, to HEp-2 cells (A) and Vero cells (B) was determined by CCK8 kit. ML-HSA was stored at 4, 24 and $37{ }^{\circ} \mathrm{C}$, respectively, for one to twelve weeks, followed by assessment of its antiviral activities against infection by RSV A2 strain (C) and Long Strain (D), respectively, were detected at the indicated time. Each sample was tested in triplicate, and the experiment was repeated twice. The data from one representative experiment were presented in mean $\pm \mathrm{SD}$.

\subsection{The Percentages of Modified Residues of arginine and Lysine Correlate with Anti-RSV Activity of}

\section{Anhydride-Modified Proteins}

Previous studies have shown that the percentages of modified arginine and lysine residues were associated with the concentration of anhydrides used [19]. To identify an anhydride with optimal concentration for producing the most effective anti-RSV agent, we used SU, ML and HP at different concentrations to modify HSA and calculated the percentages of modified arginine and lysine residues, as well as tested their antiviral activity against RSV A2 Strain and Long Strain. As shown in Figure 1A,B, with the increasing concentrations of anhydrides used, the percentages of the modified arginine and lysine residues increased, and the modified proteins gained more potent anti-RSV activity. We observed a highly significant direct correlation between the percentages of the modified 
arginine residues and the inhibitory activity against RSV A2 and Long strains (Figure 1C,D). For ML-HSA against RSV A2 and RSV Long strains, $r=-0.823 ; p=0.044$ and $r=-0.746 ; p=0.038$, respectively. The percentages of modified lysine residues also directly correlated with the anti-RSV activity of anhydride-modified proteins (Figure 1E,F). For ML-HSA against RSV A2 and RSV Long strains, $r=-0.923 ; p=0.009$ and $r=-0.875 ; p=0.022$, respectively. Neither anhydride-modified HSA nor unmodified HSA showed significant cytotoxicity at concentrations as high as $400 \mu \mathrm{M}$ (Figure $2 \mathrm{~A}, \mathrm{~B}$ ). Based on the results from our previous studies $[19,32]$ and the present study, we selected the average pH of 9.0 and $60 \mathrm{mM}$ of anhydride as the optimal parameters for subsequent experiments.

SU-modified HSA was less efficacious against infections of RSV A2 and Long Strain than HP- and ML-modified HSA. We thus excluded SU-HSA from subsequent study. Although HP-HSA had a similar, or even better, anti-RSV activity than ML-HSA, the cost of HP is much higher than that of ML. We thus selected ML-HSA for further studies. To study stability of ML-HSA, we kept ML-HSA at 4,24 , and $37^{\circ} \mathrm{C}$, respectively, for 1 to 12 weeks, and detected its anti-RSV activities at the week 1 , $2,3,4,6$, and 12 , respectively. Since its anti-RSV activity exhibited no significant changes during the 12-week storage period, ML-HSA was determined highly stable (Figure 2C,D).

\subsection{Time-of-Addition and Temperature Shift Studies Suggest that ML-HSA Inhibits RSV Infection by Blocking RSV Attachment to the Target Cells}

To determine the step of virus replication at which ML-HSA exerts its antiviral effect, ML-HSA was added at different times after RSV infection. Supernatants were then collected to determine viral infectivity at $20 \mathrm{~h}$ post-infection. As shown in Figure 3, ML-HSA was effective in inhibiting RSV replication (95\%) if added at the same time as virus inoculation. When ML-HSA was added $0.5 \mathrm{~h}$ after infection, it still displayed a powerful inhibitory activity (88\%). However, when added to the cell culture $1 \mathrm{~h}$ post-infection, the percentage of inhibition of ML-HSA was reduced to $38 \%$. When ML-HSA was added 2 to $7 \mathrm{~h}$ post-infection, no significant inhibition of viral infection was seen. These results suggest that ML-HSA inhibits RSV infection by targeting the early step of virus replication, which is viral entry.

To further explore the mechanism of action of ML-HSA, we performed a temperature shift assay based on a report that RSV could attach to cells at $4{ }^{\circ} \mathrm{C}$, while its fusion with the target cell membrane occurs at temperatures above $18{ }^{\circ} \mathrm{C}$ [33]. Thus, a viral attachment inhibitor can be expected to maintain antiviral activity if it is added to the mixture of cells and virus at $4{ }^{\circ} \mathrm{C}$, followed by washing before incubation temperature is shifted to $37^{\circ} \mathrm{C}$. As shown in Figure 4A, ML-HSA exhibited similar anti-RSV activity whether the cells were washed, or not, after it was added to the mixture of cells and virus at $4{ }^{\circ} \mathrm{C}$. Heparin, a known RSV attachment inhibitor, also showed similar anti-RSV potency whether the cells were washed or not (Figure 4B). These data indicate that ML-HSA inhibits RSV infection by blocking virus attachment to cells. 


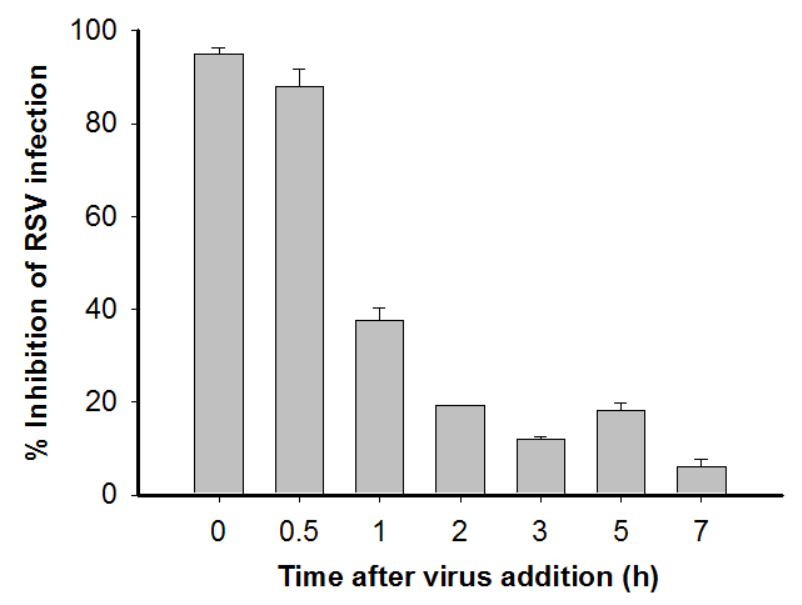

Figure 3. HSA-ML blocked RSV entry into the target cell. A time-of-addition assay was performed to determine the mechanism of action of ML-HSA. Each sample was tested in triplicate, and the experiments were repeated twice. The data from one representative experiment were presented in mean \pm SD.

A

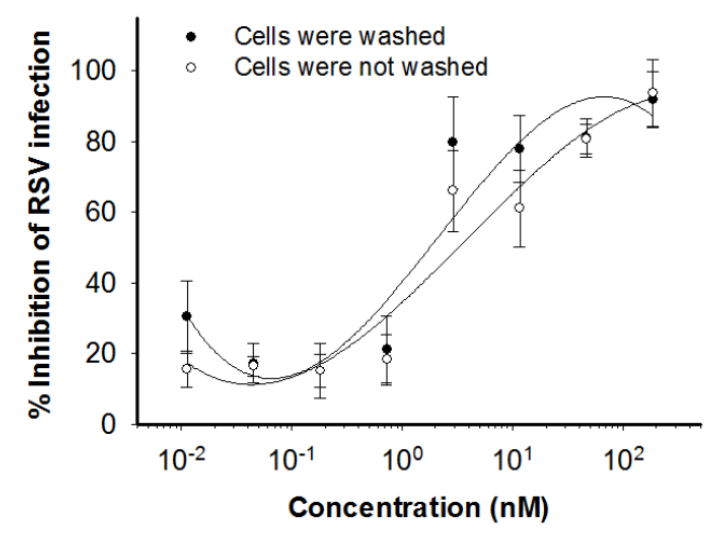

B

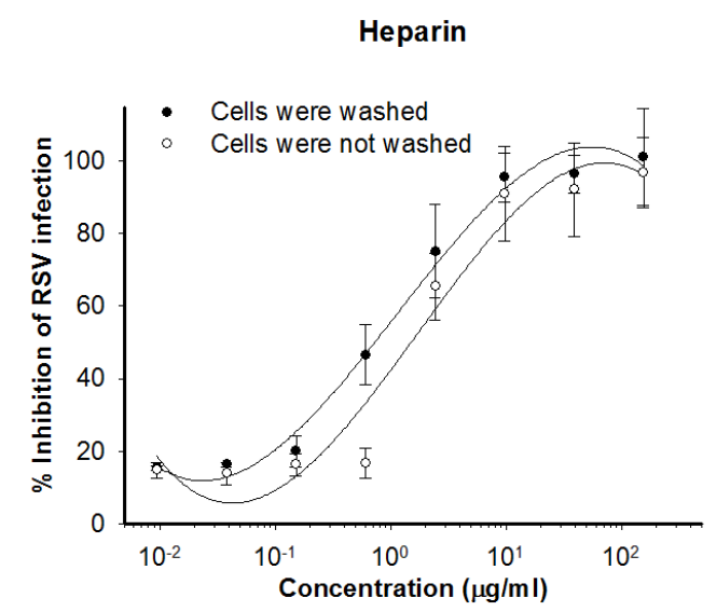

Figure 4. ML-HSA blocked RSV attachment. HEp-2 cells were incubated with RSV in the presence of serial dilutions of either ML-HSA (A) or heparin (B) at $4{ }^{\circ} \mathrm{C}$ for $1 \mathrm{~h}$, followed by washes to remove unbound virus and inhibitor, or no washing before the temperature was shifted to $37^{\circ} \mathrm{C}$. CPE was determined after 5 days and plotted as cell viability. Each diluted sample was tested in triplicate, and the experiment was repeated twice. The data from one representative experiment were presented in mean $\pm \mathrm{SD}$.

To investigate whether ML-HSA could block the $\mathrm{F}$ protein-mediated membrane fusion, we performed a cell-cell fusion assay using 293 cells expressing F protein (293-F) induced with tetracycline. As shown in Figure 5, 293-F cells (Cell) did not form syncytia without tetracycline. After addition of tetracycline, syncytia were observable under a microscope. At the concentration of $1,000 \mathrm{nM}$ ( $\sim 100$-fold higher than its IC50 for inhibiting RSV infection), ML-HSA and HSA did not inhibit the formation of syncytia. In contrast, TMC353121 at $200 \mathrm{nM}$ significantly blocked syncytium formation (Figure 5). 

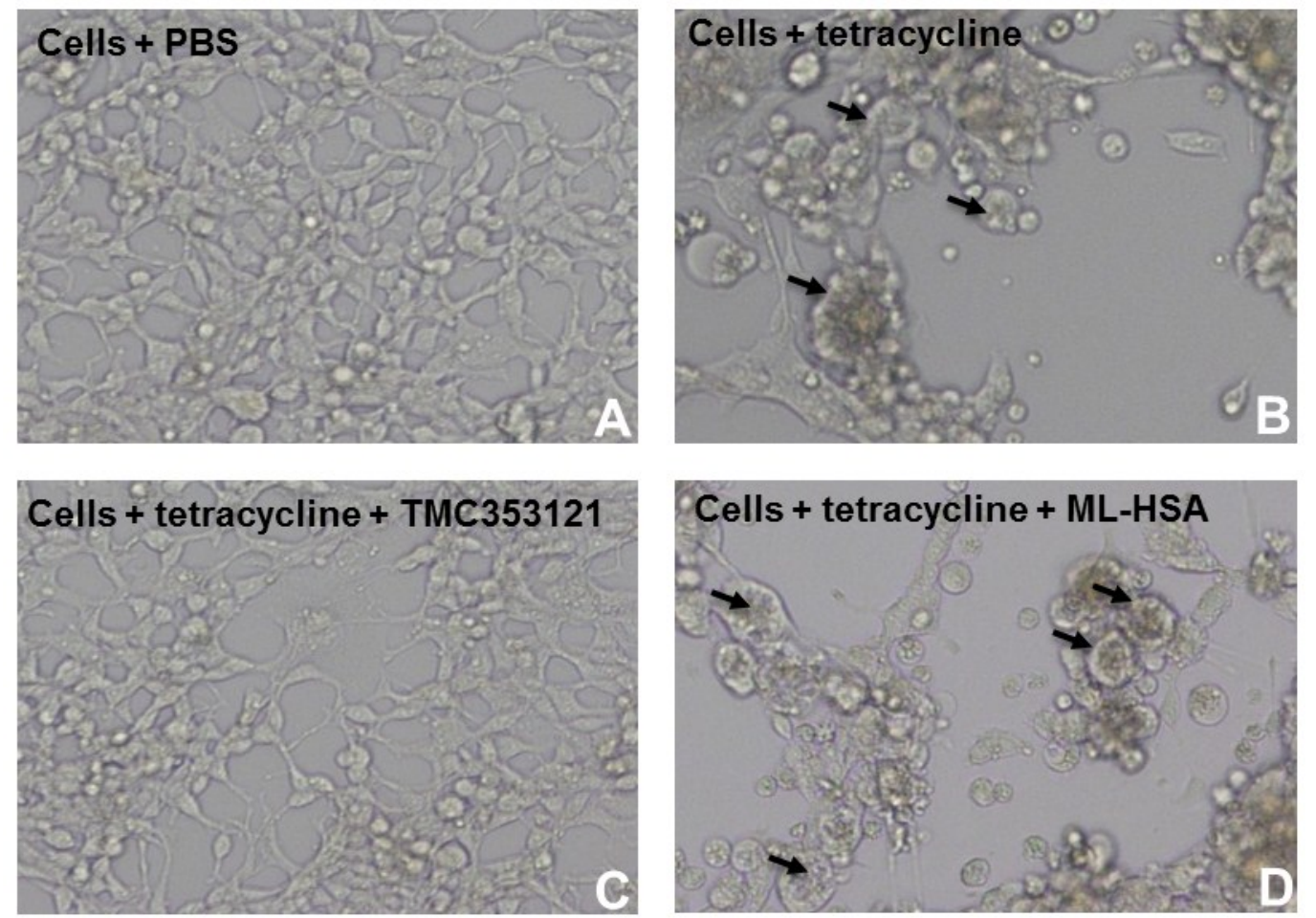

Figure 5. ML-HSA could not inhibit cell-cell fusion (or syncytium formation) mediated by $\mathrm{F}$ protein of RSV. 293-F cells expressing F protein of RSV induced by tetracycline was constructed. 293-F cells without tetracycline (A); 293-F cells with tetracycline (B), the arrows show the syncytia; 293-F cells with tetracycline in the presence of TMC353121 (200 nM), an F protein inhibitor (C); and 293-F cells with tetracycline in the presence of ML-HSA (1,000 nM) (D), and the arrows show the syncytia. Cell-cell fusion or syncytium formation was observed under a microscope.

\subsection{ML-HSA Interacted with G Protein of RSV}

To determine whether ML-HSA blocks virus attachment to cells by interacting with RSV G protein, we performed an enzyme-linked immunosorbent assay (ELISA) using anti-HSA antibody to detect the binding of ML-HSA or HSA to RSV G protein and F protein, respectively, coated on the plate. The results showed that ML-HSA bound to G protein in a dose-dependent manner. Even at the concentration as low as $2.4 \mathrm{nM}$, ML-HSA still strongly bound to $\mathrm{G}$ protein $\left(\mathrm{A}_{450}=1.62\right)$. HSA exhibited no significant binding to $\mathrm{G}$ protein at the concentration of $60 \mathrm{nM}$, although it showed weak binding at the concentration of 1,500 nM (Figure 6A). In contrast, both ML-HSA and HSA showed no significant binding to $\mathrm{F}$ protein at the concentration up to $1,000 \mathrm{nM}$ (Figure 6B). To exclude the possibility that the difference of interaction with G protein between HSA and ML-HSA might result from the reduced reactivity of the chemically modified HSA to anti-HSA antibody, we performed another ELISA using anti-HSA antibody. As shown in Figure 6C, the anti-HSA antibody bound to both HSA and ML-HSA equally well, suggesting that ML-modified HSA maintains its antigenicity to react with anti-HSA antibody. These results confirm that ML-HSA blocks virus attachment to cells via its interaction with RSV G protein. 
A

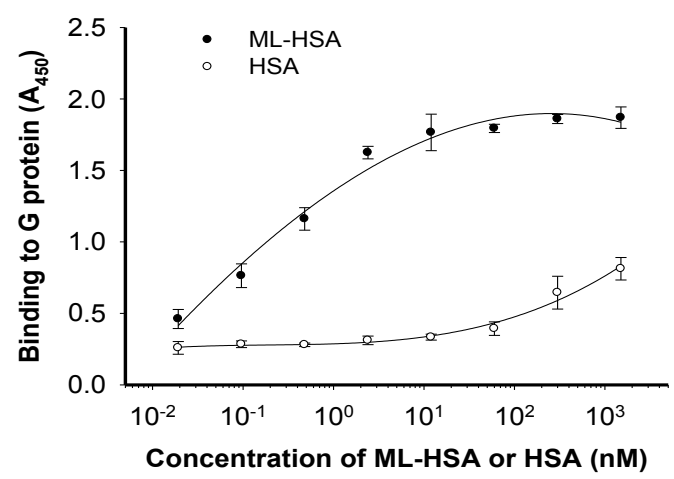

B

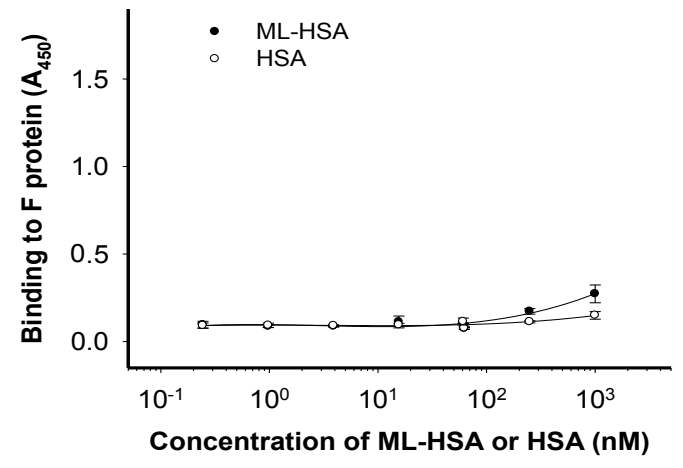

C

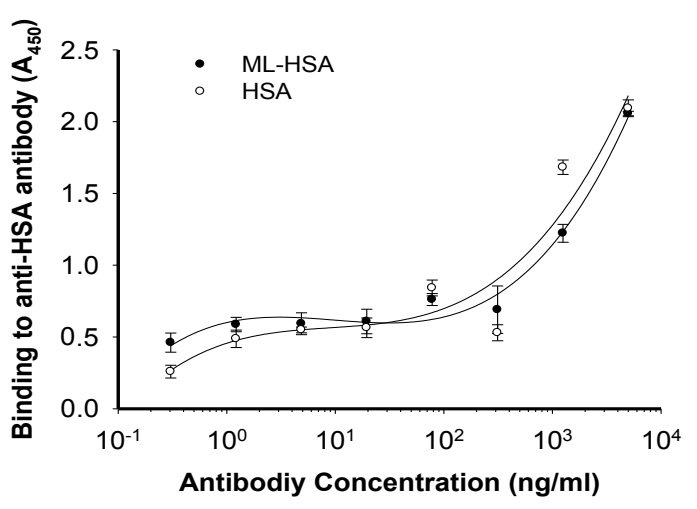

Figure 6. ML-HSA bound to RSV G protein. The wells of plates were coated with RSV G protein, HSA and ML-HSA, respectively. Binding of ML-HSA to RSV G protein (A), F protein (B) or anti-HSA antibody $(\mathbf{C})$ was determined by ELISA. Each sample was tested in triplicate, and the experiment was repeated twice. The data from one representative experiment were presented in mean $\pm \mathrm{SD}$.

\subsection{ML-HSA may Bind to the Middle Portion (Residues 145-186) of the G Protein Based on}

\section{Drug-Resistance Study}

To determine the binding site of ML-HSA in the RSV G protein, we selected a virus strain resistant to ML-HSA and compared its sensitivity to ML-HSA with that of the wild-type strain. As shown in Figure 7A, the wild-type strain showed high sensitivity to ML-HSA with an IC50 value of about $3.9 \mathrm{nM}$, while the resistant strain exhibited remarkable tolerance to ML-HSA, with an $\mathrm{IC}_{50}$ value of about $201 \mathrm{nM}$. Neither wild-type nor resistant strains showed resistance to heparin (Figure 7A). The viral RNA encoding G protein (Figure 7B) was sequenced and analyzed. The amino acid 
sequences of the $\mathrm{G}$ proteins of the wild-type strain (parent strain) and ML-HSA resistant strain were compared. We observed 8 amino acid mutations (K62I, K149R, Q152R, N157G, K158R, N161G, N169D, and N179D) in the G protein of the resistant strain, 7 of which were located in the region overlapping the residues 145-186, including the conserved domain (residues 164-186). These data suggest that ML-HSA may bind to the middle portion of the RSV G protein.

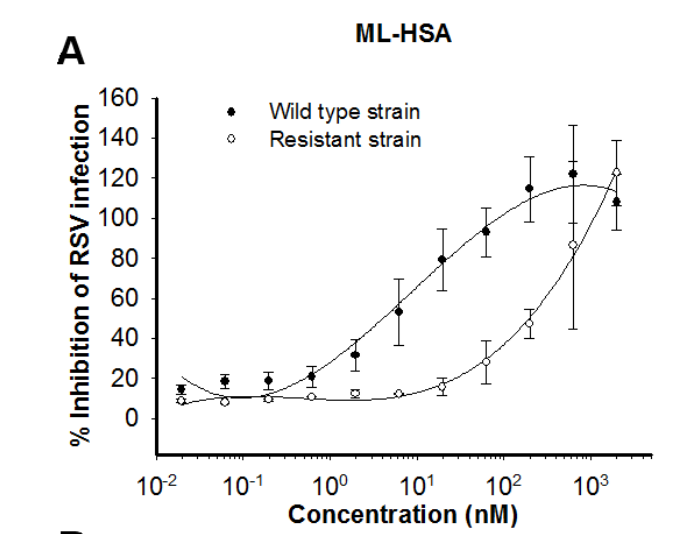

B
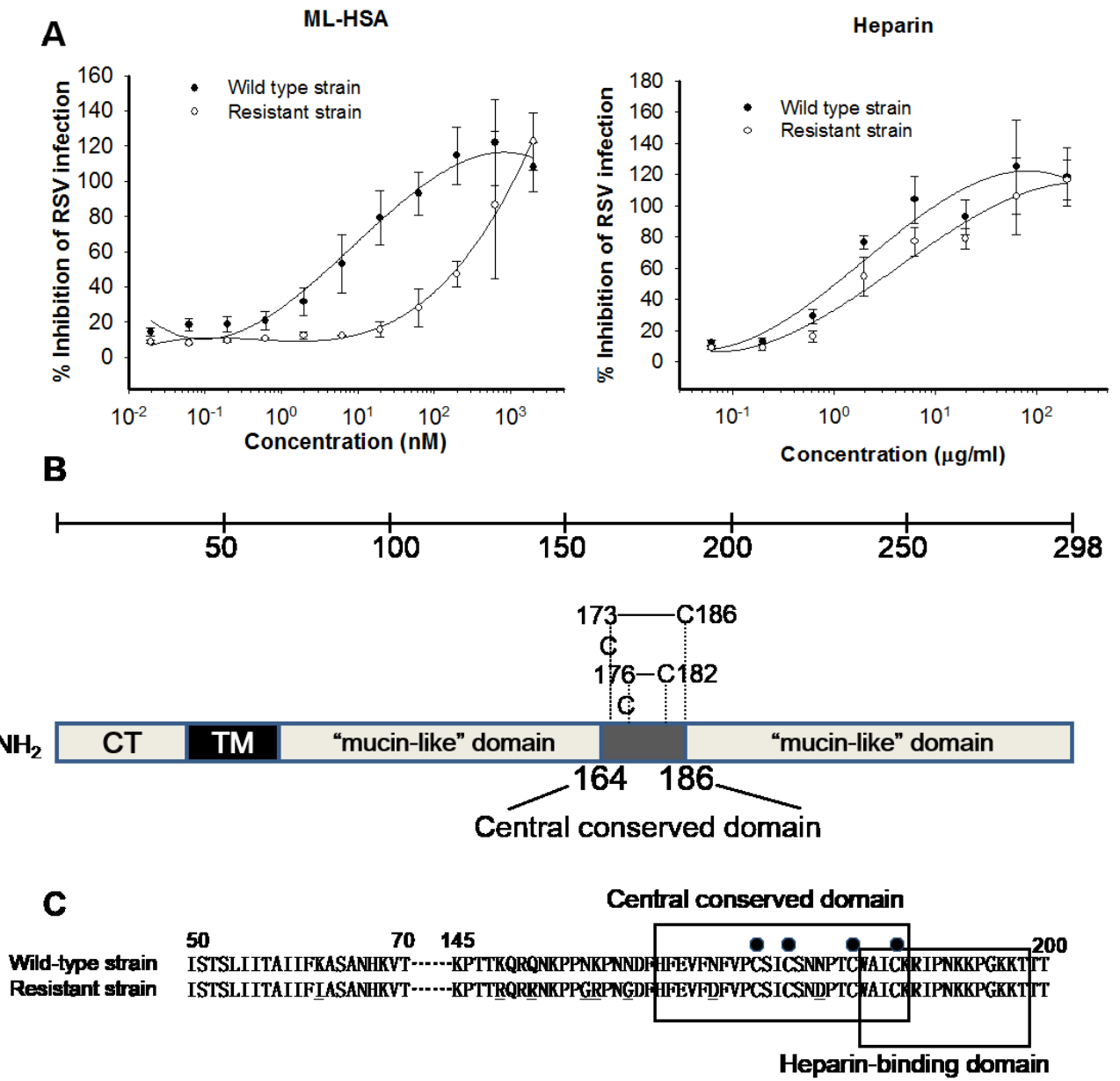

Figure 7. Determination of ML-HSA's binding sites in RSV G protein by analysis of ML-HSA-induced resistant mutations. (A) Sensitivity of the RSV mutants and wild-type to ML-HSA (left panel) and heparin (right panel) was compared. Each sample was tested in triplicate, and the experiment was repeated twice. The data from one representative experiment were presented in mean \pm SD. (B) Schematic presentation of the RSV Long Strain $G$ protein and its functional domains. The $G$ protein consists of a cytoplasmic domain (CT), a transmembrane domain (TM), two mucin-like domains, and a central conserved domain (residues 164-186). Four cysteine residues and the two corresponding disulfide bonds in the central conserved domain are indicated. (C) Amino acid sequences of the corresponding regions in the G protein of the RSV wild-type strain and ML-HSAresistant strain. Bullets above the sequences indicate the four conserved cysteine residues. The central conserved domain and the heparin-binding domain are shown in boxes, respectively. The mutated amino acid residues in the G protein of ML-HSA-resistant strain are underlined. 


\subsection{ML-HSA Inactivated RSV when RSV and ML-HSA Were Mixed before Intranasal} Administration to Mice

A mouse model of RSV infection was used to examine the in vivo inhibitory activity of ML-HSA. BALB/c mice $(n=8)$ were intranasally administered with ML-HSA at a single dose of 5, 15, 50 or $75 \mathrm{mg} / \mathrm{kg}$, respectively, mixed with RSV Long Strain $\left(2.1 \times 10^{5} \mathrm{PFU}\right)$. Four days post-infection, the mice were sacrificed, and viral titers in the lung homogenates were measured. As shown in Figure 8A, the viral titer in the untreated mice was in the range of 3.4 to 4.4 (mean $=3.98) \log 10$ PFU per gram of lung tissue. The mean viral titers in the lungs of the mice treated with 5 and $15 \mathrm{mg} / \mathrm{kg}$ of ML-HSA were 3.97 and $3.7 \log 10$ PFU per gram of lung tissue, respectively, thus showing no significant difference from the untreated group $(p>0.05)$. The mean viral titers in the lungs of mice treated with 50 and $75 \mathrm{mg} / \mathrm{kg}$ of ML-HSA were 2.41 and $2.25 \log 10$ PFU per gram of lung tissue, respectively, which were significantly lower than those in the untreated control group ( $p<0.01$ for both groups). Thus, the RSV titer in the lungs of mice treated with $5,15,50$, and $75 \mathrm{mg} / \mathrm{kg}$ of ML-HSA was reduced by $2.3 \%, 46.8 \%, 97.3 \%$ and $98.1 \%$, respectively (Figure $8 \mathrm{~B}$ ), suggesting that ML-HSA, at the concentration of 50 and $75 \mathrm{mg} / \mathrm{kg}$, can very effectively inhibit RSV replication in vivo.

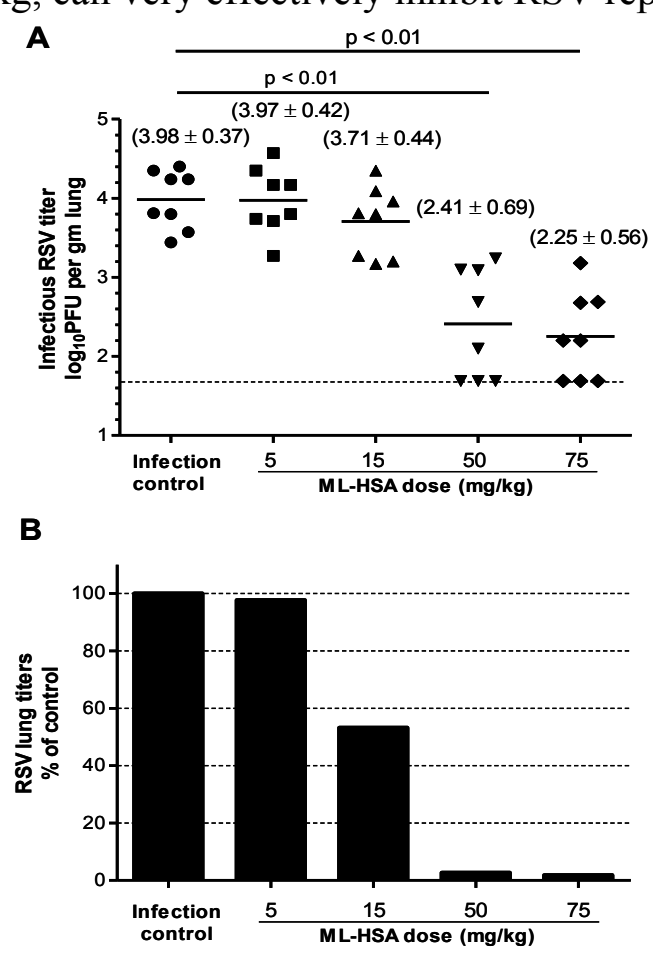

Figure 8. Inhibitory activity of ML-HSA on in vivo RSV infection in BALB/c mice. (A) ML-HSA at different concentrations was mixed with the RSV Long Strain before intranasal inoculation. The infectious RSV titer in the mouse lung was expressed as the $\log 10$ PFU per gram of lung tissue. Each data point represents the RSV titer for each individual animal in the respective treatment cohort. The horizontal line, drawn in each cohort, marks the geometric mean RSV titer of the group. The horizontal hatched line, across the graph, represents the RSV titer at the limit of assay detection. (B) Percentages of viral titer (geometric mean) in the lungs of ML-HSA-treated cohorts relative to infection control group (without ML-HSA treatment). 


\subsection{ML-HSA Exhibited Prophylactic Efficacy in the Mouse Model against RSV Infection}

To evaluate the prophylactic efficacy of ML-HSA in the mouse model against RSV infection, we intranasally administered ML-HSA to mice at a dose of $100 \mathrm{mg} / \mathrm{kg} 30$ or $15 \mathrm{~min}$ prior to RSV inoculation. Four days post-infection, PFU titers were determined using the plaque assay. The viral control cohort showed a mean of $3.79 \log 10$ PFU per gram of lung tissue. The groups administered with ML-HSA 15 and $30 \mathrm{~min}$, respectively, before RSV infection had a mean of 3.11 and $2.89 \log 10$ PFU per gram of lung tissue, respectively (Figure 9A). The viral titers in the mice treated with ML-HSA 15 and $30 \mathrm{~min}$, respectively, before RSV infection were significantly lower than those of the untreated mice ( $p=0.045$ and 0.031 , respectively), with about $68 \%$ and $70 \%$ reduction of the viral titers in the lungs, respectively (Figure 9B). This result suggests that intranasal administration of ML-HSA is effective in preventing RSV infection.

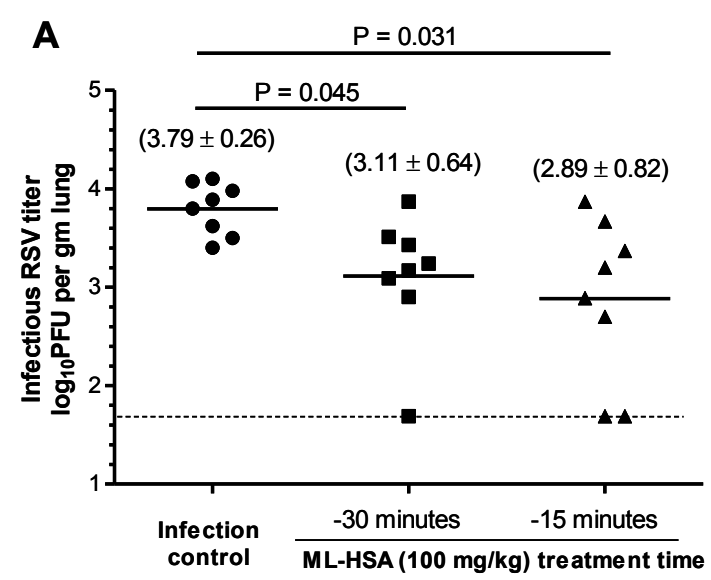

B

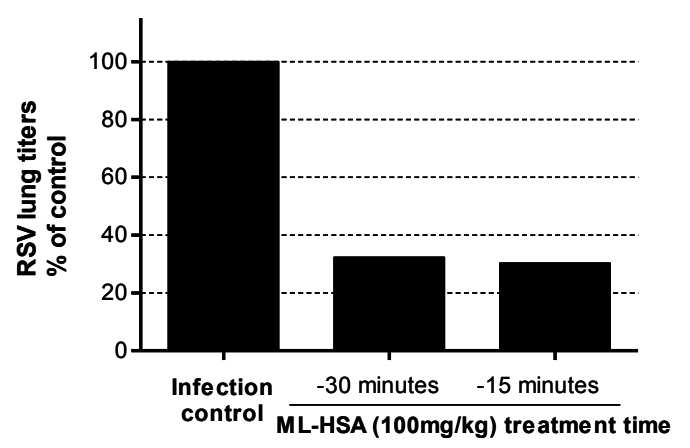

Figure 9. Prophylactic efficacy of ML-HSA against RSV infection in BALB/c mice. (A) ML-HSA (100 mg/kg) was administered 15 and $30 \mathrm{~min}$, respectively, before RSV intranasal inoculation. The infectious RSV lung titer in the mouse lung was expressed as the $\log 10$ PFU per gram of lung tissue. Each data point represents the RSV titer for each individual animal in the respective treatment cohort. The horizontal line, drawn in each cohort, marks the geometric mean RSV titer of the group. The horizontal hatched line, across the graph, represents the RSV titer at the limit of assay detection. (B) Percentages of viral titer (geometric mean) in the lungs of ML-HSA-treated cohorts relative to infection control group (without ML-HSA treatment). 


\section{Discussion}

In the present study, we compared the in vitro anti-RSV activity of $\beta$-LG, BSA, OVA, and HSA modified with HP, ML and SU, respectively. While all these anhydride-modified proteins exhibited potent inhibitory activity against infection by RSV A2 and Long strains, HP- and ML-modified BSA and HSA were found to be more effective than other anhydride-modified proteins (Table 1). We selected ML-modified HSA for further study because (1) HSA is safer than BSA for human use, as some infants may be allergic to bovine proteins; and (2) the purchase price of HP is much higher than that of ML, making the production costs of ML-HSA much lower than those of HP-HSA. In addition, ML is a common anhydride used in pharmaceuticals. McCormick et al. have reported that maleic anhydride-divinyl ether copolymer (MVE-2) inhibits mammary and urinary bladder carcinogenesis [34]. Xie et al. demonstrated that FB006M, an anti-HIV-1 peptide modified with a ML derivative, exhibited no significant toxic effect to animals and human [35]. Based on our toxicity tests, ML-HSA showed no detectable cytotoxicity to HEp-2 and Vero cells (Figure 2).

HSA consists of 585 amino acids, including 59 lysine residues (10.1\%) and 27 arginine residues (4.6\%). Our previous studies have shown that modification of these positively charged amino acid residues converts the protein into a potent HIV entry inhibitor [36] and that the percentage of the modified lysine and arginine residues is dependent on the concentration of anhydrides and $\mathrm{pH}$ of the reaction system $[13,19,34]$. In this study, we found that the optimal $\mathrm{pH}$ value of system reaction was 9.0, while the optimal concentration of ML was $60 \mathrm{mM}$ for preparation of ML-HSA with the most potent inhibitory activity against RSV infection (Figure 1A,B).

In the time-of-addition assay, ML-HSA exhibited significantly decreased inhibitory activity against RSV when it was added to the culture of cells and virus one hour post-viral infection (Figure 3), suggesting that ML-HSA inhibits RSV infection by targeting the early stages of viral replication. We then used a temperature shift assay to determine whether ML-HSA blocks viral attachment or binding to target cells based on the principle that RSV can attach or bind to target cells at $4{ }^{\circ} \mathrm{C}$, while delaying cell fusion until the temperature is shifted to $18{ }^{\circ} \mathrm{C}$ or higher. Thus, if ML-HSA can block virus attachment to, but not fusion with the target cells, it will still retain inhibitory activity against RSV replication after the unbound ML-HSA and virus are removed following virus attachment at $4{ }^{\circ} \mathrm{C}$, but before the temperature is raised to $18{ }^{\circ} \mathrm{C}$ or higher [33]. As shown in Figure 4, ML-HSA had similar $\mathrm{IC}_{50}$ shether or not when the unbound ML-HSA was removed before the temperature was shifted to $37^{\circ} \mathrm{C}$, confirming that ML-HSA blocks the attachment of RSV to the target cells, possibly by its interaction with the viral G protein. Indeed, ML-HSA binds with the G protein of RSV in a dose-dependent manner, as shown in ELISA (Figure 6A). In contrast, both ML-HSA and HSA showed no significant binding to $\mathrm{F}$ protein at the concentration up to $1000 \mathrm{nM}$ (Figure 6B). However, our results, as herein presented, could not rule out the possibility that ML-HSA might also interact with F protein at a higher concentration in a non-specific way. In addition, the purified $\mathrm{F}$ protein that was tested here is likely in a post-fusion conformation, which is expected to be different from the pre-fusion conformation of RSV F protein. Therefore, further determining whether ML-HSA binds to the pre-fusion form of $\mathrm{F}$ protein is warranted.

The binding site of ML-HSA in viral G protein was revealed by induction of RSV mutants with resistance to ML-HSA. Most of the mutated residues are located in the region spanning residues 
145-186, suggesting that ML-HSA may bind to the middle portion of the G protein. Interestingly, two Asn residues in this region were substituted with the negatively charged Asp residues (N169D and N179D), leading to increased net negative charges in the binding site of ML-HSA in the G protein, possibly resulting in the decreased electrostatic interaction between the negatively charged ML-HSA and $\mathrm{G}$ protein of RSV.

To the best of our knowledge, no RSV vaccine is currently available [37]. Palivizumab, an anti-RSV $\mathrm{mAb}$, has been used as an immunoprophylaxis to prevent RSV infection in infants at high risk of RSV infection, including those with a history of prematurity, chronic lung disease, and congenital heart disease [38]. However, its high cost is prohibitive in low-income countries. As demonstrated in this study, ML-HSA is highly effective in inhibiting RSV infection in vitro in cell culture and in vivo in a mouse model. Furthermore, ML-HSA significantly reduced the titers of RSV in the lungs of mice when it was administered intranasally before challenge with RSV. Therefore, ML-HSA may be used as a prophylactic agent to prevent RSV infection in infants at high-risk or immunocompromised persons of RSV infection. However, unlike palivizumab, which must be intramuscularly injected by nurses or doctors in hospitals, clinics or doctors' offices, ML-HSA can be intranasally administered by the parents of infants in the home or other places. Because of its intranasal application, ML-HSA may be approved for over-the-counter use. Palivizumab must be maintained and transported under low temperature, while ML-HSA may be kept at room temperature for at least 12 weeks based on its high stability (Figure 2C,D). Our previous study has also shown that the HP-modified LG protein maintained its antiviral activity for 3 months when it was kept at room temperature $[12,38]$. Therefore, ML-HSA might be made into a nasal spray or any other portable form for use with infants at high risk or immunocompromised persons before travelling to high-risk areas, such as hospitals or densely populated public areas, or used directly at such places to acquire protection against RSV cross-infection for a period. In our mouse model of RSV infection, ML-HSA administered $30 \mathrm{~min}$ prior to RSV infection yielded a significant protection. However, purified RSV with a high titer was used to infect BALB/c mice, differing from human infection with RSV virions which, in high-risk areas, are suspended in the air with low titer and, hence, easily spread. Therefore, in actual use, longer protection might be obtained with ML-HSA against RSV infection. While this topic outside the scope of the present work, further formulation development and clinical trials make this determination.

In conclusion, maleic anhydride-modified human serum albumin (ML-HSA) exhibited potent inhibitory activities against RSV infection in vitro and in vivo by binding to the viral $\mathrm{G}$ protein and blocking RSV attachment to the target cells. ML-HSA administered intranasally before RSV infection led to a significant reduction of viral titers in the lungs of mice. These results suggest that ML-HSA is a promising therapeutic candidate for further development into an effective, safe, and affordable intranasal regimen for pre-exposure prophylaxis of RSV infection in high-risk populations, including infants born prematurely with chronic lung or congenital heart disease, elderly people and immunocompromised adults. 


\section{Acknowledgments}

We are grateful to Bin Wang at Fudan University for providing the vectors encoding RSV G and F proteins and A2 strains. This work was supported by grants from the National Science Fund of China (81173098 and 81361120378 to S.J., 81373456 to L.L., 81273204 to J.X.), and sponsored by National High Technology Research and Development Program of China (SQ2015AA0201116) and the Shanghai Pujiang Program (13PJD004).

\section{Author Contributions}

Zhiwu Sun performed most experiments and wrote the draft of the manuscript. Qian Wan prepared many reagents for the experiments. Ran Jia helped performed animal experiments. Shuai Xia helped in the preparation of modified proteins. Yuan Li helped with virus purification. Qi Liu and Wei Xu helped with the animal experiments. Lanying Du provided expertise on animal experiments. Lu Lu and Shibo Jiang supervised this study, and edited this paper.

\section{Conflicts of Interest}

The authors declare no conflict of interest.

\section{References}

1. Falsey, A.R.; Hennessey, P.A.; Formica, M.A.; Cox, C.; Walsh, E.E. Respiratory syncytial virus infection in elderly and high-risk adults. N. Engl. J. Med. 2005, 352, 1749-1759.

2. Collins, P.L.; Crowe, J.E.J. Respiratory syncytial virus and Metapneumovirus. In Fields Virology, 5th ed.; Knipe, D.M., Howley. P.M., Griffin, D.E., Lamb, R.A., Martin, M.A., Roizman, B., Straus, S.E., Eds.; Lippincott Williams \& Wilkins: Philadelphia, PA, USA, 2007; Volume 2, pp. 1601-1646.

3. Collins, P.L.; Melero, J.A. Progress in understanding and controlling respiratory syncytial virus: Still crazy after all these years. Virus Res. 2011, 162, 80-99.

4. Nair, H.; Noke, D.J.; Gessner, B.D.; Dherani, M.; Madhi, S.A.; Singleton, R.J.; O'Brien, K.L.; Roca, A.; Wright, P.F.; Bruce, N.; et al. Global burden of acute lower respiratory infections due to respiratory syncytial virus in young children: A systematic review and meta-analysis. Lancet 2010, 375, 1545-1555.

5. Hall, C.B.; Weinberg, G.A.; Iwane, M.K.; Blumkin, A.K.; Edwards, K.M.; Staat, M.A.; Auinger, P.; Griffin, M.R.; Poehling, K.A.; Erdman, D.; et al. The Burden of Respiratory Syncytial Virus Infection in Young Children. N. Engl. J. Med. 2009, 360, 588-598.

6. Hacking, D.; Hull, J. Respiratory syncytial virus - Viral biology and the host response. J. Infect. 2002, 45, 18-24.

7. Simoes, E.A. Respiratory syncytial virus infection. Lancet 1999, 354, 847-852.

8. Wu, H.; Pfarr, D.S.; Losonsky, G.A.; Kiener, P.A. Immunoprophylaxis of RSV infection: Advancing from RSV-IGIV to palivizumab and motavizumab. Curr. Top Microbiol. Immunol. 2008, 317, 103-123. 
9. Wang, D.; Bayliss, S.; Meads, C. Palivizumab for immunoprophylaxis of respiratory syncytial virus (RSV) bronchiolitis in high-risk infants and young children: A systematic review and additional economic modelling of subgroup analyses. Health Technol. Assess 2011, 15, i-iii.

10. Committee on infectious diseases and bronchiolitis gudelines committee. Updated guidance for palivizumab prophylaxis among infants and young children at increased risk of hospitalization for respiratory syncytial virus. Pediatrics 2014, 134, 415-420.

11. Meissner, H.C.; Kimberlin, D.W. RSV Immunoprophylaxis: Does the Benefit Justify the Cost? Pediatrics 2013, 132, 915-918.

12. Lu, L.; Yang, X.; Li, Y.; Jiang, S. Chemically modified bovine beta-lactoglobulin inhibits human papillomavirus infection. Microbes Infect. 2013, 15, 506-510.

13. Neurath, A.R.; Jiang, S.; Strick, N.; Lin, K.; Li, Y.Y.; Debnath, A.K. Bovine beta-lactoglobulin modified by 3-hydroxyphthalic anhydride blocks the CD4 cell receptor for HIV. Nat. Med. 1996, 2, 230-234.

14. Neurath, A.R.; Debnath, A.K.; Strick, N.; Li, Y.Y.; Lin, K.; Jiang, S. Blocking of CD4 cell receptors for the human immunodeficiency virus type 1 (HIV-1) by chemically modified bovine milk proteins: Potential for AIDS prophylaxis. J. Mol. Recognit. 1995, 8, 304-316.

15. Razinkov, V.; Gazumyan, A.; Nikitenko, A.; Ellestad, G.; Krishnamurthy, G. RFI-641 inhibits entry of respiratory syncytial virus via interactions with fusion protein. Chem. Biol. 2001, $8,645-659$.

16. Kluwe, W.M. Carcinogenic Potential of Phthalic Acid Esters and Related-Compounds: Structure-Activity-Relationships. Environ. Health Perspect 1986, 65, 271-278.

17. Li, L.; He, L.; Tan, S.; Guo, X.; Lu, H.; Qi, Z.; Pan, C.; An, X.; Jiang, S.; Liu, S. 3-Hydroxyphthalic Anhydride-Modified Chicken Ovalbumin Exhibits Potent and Broad Anti-HIV-1 Activity: A Potential Microbicide for Preventing Sexual Transmission of HIV-1. Antimicrob. Agents Chemother. 2010, 54, 1700-1711.

18. Yamasaki, R.B.; Vega, A.; Feeney, R.E. Modification of Available Arginine Residues in Proteins by Para-Hydroxyphenylglyoxal. Anal. Biochem. 1980, 109, 32-40.

19. Li, L.; Qiao, P.; Yang, J.; Lu, L.; Tan, S.; Lu, H.; Zhang, X.; Chen, X.; Wu, S.; Jiang, S.; et al. Maleic anhydride-modified chicken ovalbumin as an effective and inexpensive anti-HIV microbicide candidate for prevention of HIV sexual transmission. Retrovirology 2010, 7, doi:10.1186/1742-4690-7-37.

20. Lu, L.; Liu, Q.; Zhu, Y.; Chan, K.H.; Qin, L.; Li, Y.; Wang, Q.; Chan, J.F.; Du, L.; Yu, F.; et al. Structure-based discovery of Middle East respiratory syndrome coronavirus fusion inhibitor. Nat. Commun. 2014, 5, doi:10.1038/ncomms4067.

21. Cianci, C.; Yu, K.L.; Combrink, K.; Sin, N.; Pearce, B.; Wang, A.; Civiello, R.; Voss, S.; Luo, G.; Kadow, K.; et al. Orally active fusion inhibitor of respiratory syncytial virus. Antimicro. Agents Chemother. 2004, 48, 413-422.

22. Huntley, C.C.; Weiss, W.J.; Gazumyan, A.; Buklan, A.; Feld, B.; Hu, W.; Jones, T.R.; Murphy, T.; Nikitenko, A.A.; O'Hara, B.; et al. RFI-641, a potent respiratory syncytial virus inhibitor. Antimicro. Agents Chemother. 2002, 46, 841-847. 
23. Andries, K.; Moeremans, M.; Gevers, T.; Willebrords, R.; Sommen, C.; Lacrampe, J.; Janssens, F.; Wyde, P.R. Substituted benzimidazoles with nanomolar activity against respiratory syncytial virus. Antivir. Res. 2003, 60, 209-219.

24. Douglas, J.L.; Panis, M.L.; Ho, E.; Lin, K.Y.; Krawczyk, S.H.; Grant, D.M.; Cai, R.; Swaminathan, S.; Cihlar, T. Inhibition of respiratory syncytial virus fusion by the small molecule VP-14637 via specific interactions with F protein. J. Virol. 2003, 77, 5054-5064.

25. Kahn, J.S.; Schnell, M.J.; Buonocore, L.; Rose, J.R. Recombinant vesicular stomatitis virus expressing respiratory syncytial virus (RSV) glycoproteins: RSV fusion protein can mediate infection and cell fusion. Virology 1999, 254, 81-89.

26. Roymans, D.; de Bondt, H.L.; Arnoult, E.; Geluykens, P.; Gevers, T.; van Ginderen, M.; Verheyen, N.; Kim, H.; Willebrords, R.; Bonfanti, J.F.; et al. Binding of a potent small-molecule inhibitor of six-helix bundle formation requires interactions with both heptad-repeats of the RSV fusion protein. Proc. Natl. Acad. Sci. USA 2010, 107, 308-313.

27. Lu, L.; Pan, C.; Li, Y.; Lu, H.; He, W.; Jiang, S. A bivalent recombinant protein inactivates HIV-1 by targeting the gp41 prehairpin fusion intermediate induced by CD4 D1D2 domains. Retrovirology 2012, 9, doi:10.1186/1742-4690-9-104.

28. Kimura, K.; Ishioka, K.; Hashimoto, K.; Mori, S.; Suzutani, T.; Bowlin, T.L.; Shigeta, S. Isolation and characterization of NMSO3-resistant mutants of respiratory syncytial virus. Antivir. Res. 2004, 61, 165-171.

29. Morton, C.J.; Cameron, R.; Lawrence, L.J.; Lin, B.; Lowe, W.; Luttick, A.; Mason, A.; Kimm-Breschkin, J.; Parker, M.W.; Ryan, J.; et al. Structural characterization of respiratory syncytial virus fusion inhibitor escape mutants: Homology model of the F protein and a syncytium formation assay. Virology 2003, 311, 275-288.

30. Cianci, C.; Genovesi, E.V.; Lamb, L.; Medina, I.; Yang, Z.; Zadjura, L.; Yang, H.; D'Arienzo, C.; Sin, N.; Yu, K.L.; et al. Oral efficacy of a respiratory syncytial virus inhibitor in rodent models of infection. Antimicrob. Agents Chemother. 2004, 48, 2448-2454.

31. Sudo, K.; Watanabe, W.; Mori, S.; Konno, K.; Shigeta, S.; Yokota, T. Mouse model of respiratory syncytial virus infection to evaluate antiviral activity in vivo. Antivir. Chem. Chemother. 1999, 10, 135-139.

32. Graham, B.S.; Perkins, M.D.; Wright, P.F.; Karzon, D.T. Primary Respiratory Syncytial Virus-Infection in Mice. J. Med. Virol. 1988, 26, 153-162.

33. Srinivasakumar, N.; Ogra, P.L.; Flanagan, T.D. Characteristics of Fusion of Respiratory Syncytial Virus with Hep-2 Cells as Measured by R18 Fluorescence Dequenching Assay. J. Virol. 1991, 65, 4063-4069.

34. Mccormick, D.L.; Becci, P.J.; Moon, R.C. Inhibition of Mammary and Urinary-Bladder Carcinogenesis by A Retinoid and A Maleic Anhydride-Divinyl Ether Co-Polymer (Mve-2). Carcinogenesis 1982, 3, 1473-1477.

35. Xie, D.; Yao, C.; Wang, L.; Min, W.; Xu, J.; Xiao, J.; Huang, M.; Chen, B.; Liu, B.; Li, X.; et al. An Albumin-Conjugated Peptide Exhibits Potent Anti-HIV Activity and Long In Vivo Half-Life. Antimicro. Agents Chemother. 2010, 54, 191-196. 
36. Li, L.; Qiu, J.; Lu, L.; An, S.; Qiao, P.; Jiang, S.; Liu, W. 3-Hydroxyphthalic anhydride-modified human serum albumin as a microbicide candidate inhibits HIV infection by blocking viral entry. J. Antimicrob. Chemother. 2013, 68, 573-576.

37. Sun, Z.; Pan, Y.; Jiang, S.; Lu, L. Respiratory Syncytial Virus Entry Inhibitors Targeting the F Protein. Viruses 2013, 5, 211-225.

38. SYNAGIS ${ }^{\circledR}$ (PALIVIZUMAB) Instructions for Intramuscular Administration. Available online: http://www.accessdata.fda.gov/drugsatfda_docs/label/2002/palimed102302LB.pdf (accessed on 2 December 1999).

(C) 2015 by the authors; licensee MDPI, Basel, Switzerland. This article is an open access article distributed under the terms and conditions of the Creative Commons Attribution license (http://creativecommons.org/licenses/by/4.0/). 